\title{
Twitter: an introduction to microblogging for health librarians
}

\author{
Dean Giustini and Mary-Doug Wright
}

Twitter is a way of life...people the world over [are] engaged in timely snippet conversations that fit into 140 character chunks [1]

Don't hate me because I'm not a big fan of Twitter [2].

\section{Introduction}

In this article, we introduce health librarians to Twitter and examine its potential (as well as its problems) as a platform for sharing and seeking information. In focusing on many practical aspects of using Twitter, we also critique microblogging as a way to broadcast what you are doing, thinking, or saying. Twitter's significance is greater than simply the diffusion of transient forms of information within social networks; more generally, we believe that Twitter is increasingly symbolic of a tech-oriented culture engaged in constant peer-to-peer sharing, surveillance, and mass collaboration [3].

Twitter is a Web 2.0 phenomenon with no signs of slowing down. Along with Jaiku and Plurk (two other popular microblogging tools), Twitter is riding a wave of enthusiasm around the world [4]. Twitter enjoyed an exponential growth in popularity in 2008. As of January 2009, there were almost 4.5 million Twitter users worldwide; this represents a massive $752 \%$ increase in 2008 alone [5].

According to HubSpot, one million new visitors viewed Twitter in December 2008 [6]. In terms of increased numbers of users and hype, the rise of Twitter mirrors the interest shown in the past with other Web 2.0 tools such as Facebook, Wikipedia, and YouTube.

Is Twitter a useful communication tool for health librarians? A number of librarians are experimenting with microblogging, but we have noted a lack of participation among the health library community $[7,8]$. Although the use of Twitter was slow in 2007 and rose sharply in 2008, it will likely gain even more attention in 2009 [9]. Twitter is representative of a new generation of information tools-including handhelds and mobiles like the iPhone and BlackBerry-that help to promote ambient information access and "on-the-go" communication [10].

\section{What is Twitter?}

Twitter is best described as a social networking tool and microblogging service that enables the sharing of brief snippets of information to a maximum of 140 characters (about 15 words).

People on Twitter (called twitterers) update each other via a type of "status update" feature similar to what is seen in Facebook and LinkedIn. Status updating is a way for members of a social network to share personal information ("momentary states") by updating each other regularly on their whereabouts and activities. Simply put, status updates are about asserting your digital presence, little more. On Twitter, updates are more frequent, have multidimensionality, and may number several per hour.

Twitter updates also have a markedly different "feel" from Facebook and LinkedIn in temporal and structural terms. The major reason is that frequent updates are Twitter's "raison d'etre", whereas in Facebook, status update is one part of a larger platform for peer-to-peer sharing. Some users suggest that twittering falls between blogging and instant messaging or midway along a continuum of Web 2.0 communication. Twitter's main purpose is to increase the speed and flow of information among social groups in real time and to open up lines of communication across a distributed, mostly public network [11].

One of Twitter's main attributes is the ability to follow people outside your social network and with whom you normally do not come into contact. Twitter is easy to use and is informative if you follow (or subscribe to) interesting people. (Give it a try. It takes time to build your network, so be persistent.) As an index to "global conversation" (what people are thinking and saying right now) Twitter provides a means to stay connected to what is being said in numerous channels of chat via a single point of entry [12].

D. Giustini. ${ }^{1}$ Biomedical Branch Library, Gordon and Leslie Diamond Health Care Centre, 2775 Laurel Street, Floor 2, Vancouver, BC V5Z 1M9, Canada (e-mail: dean.giustini@ubc.ca).

M.-D. Wright. Apex Information, 101-1857 West 4th Avenue, Vancouver, BC V6J 1M4, Canada (e-mail: mdwright@apexinformation.com).

${ }^{1}$ Corresponding author. 
Twitter is accessible via a desktop computer or mobile. Its interface allows users to post messages to be read anywhere within the Twitterverse, unless a user makes his or her feed completely private. (A new free microblogging service called Yammer, sometimes called Twitter for businesses, can be used for completely private social networking within organizations for $\$ 1.00$ per user per month [13].) Twitter posts are sent to a centralized Web site, either directly or through an instant messaging tool, by e-mail, or by one of many third-party clients currently available [14]. Since Twitter is accessible over the Internet, users aren't tied to any one specific computer or location. One of Twitter's many charms is that conversation can be carried on from anywhere, whether at work, at home, or while traveling.

\section{Twitter etiquette and lingo}

Twitter etiquette is similar to that observed on other micromedia tools. Being concise and pithy are definite attributes. The flow of information and one-liners on Twitter can be overwhelming, but many people find watching the speedy volley of information back and forth to be invigorating.

The streams of information help to provoke clear thinking and ultimately in working efficiently. Reading posts is like meeting around the office water cooler and sharing organizational information. Some Twitterers say that face-to-face meetings are more efficient when some discussion has taken place first on Twitter [15].

Users have created their own vocabulary to describe Twitter, some of which can be quite amusing. Learning the lingo may be important to understand the volley of posts and how Twitter is discussed. For example, regular posts are called "tweets". When you make a mistake, it's termed a "mistweet".

One of the terms used as an endearment for twitterers you follow is "my tweeps" or collectively, "my tweeple". The word "blogosphere" describes the world of blogging; the world of Twitter is called the "twitosphere". High profile twitterers are called the "twitterati".

When Twitter was first released in 2006, some bloggers roundly criticized it saying it was a waste of time $[16,17]$. Before many early users could get the hang of twittering, they sent pointless posts such as "I'm chillin"” or "enjoying a latte"-mundane and pointless, even though far from incorrect. What is the point behind these types of shared statements, many wondered?

In time, serious Twitter communities began to develop. The true potential of Twitter as a current awareness and information tool began to emerge in 2007 [18,19]. Twitter also attracted the attention of corporations, governments, and other organizations in 2008. Twitter is now at a stage where it is challenging some of the ways in which we think and work in the digital age.

\section{How does it work?}

The main goal in building your network on Twitter is to "friend" people and benefit from talking to them. Think of the tweets between people as consisting of a wide range of applications, and not just the social aspects. Since everyone within Twitter exchanges posts to the simple question "What are you doing?", the service gets at microforms of cognition that few other technologies can claim to do. What we find is that Twitter is a trigger for thinking and brainstorming.

Is Twitter indicative of our over-reliance on connective technologies in the 21st century? Do microtechnologies fragment the way we think and work [20]? These are some of the questions that we are asking, particularly because we believe that health librarians may already be saturated by technology and may not want to use Twitter (or may not see its potential value relative to its time commitment).

So how does one begin to share one's intellectual minutiae in a social network like Twitter? Is it time-consuming?

An icebreaker of some kind is always helpful in getting conversation going. Some people compare Twitter to eavesdropping. Once you get the gist of a thread, the opportune moment to share your thoughts will present itself. On Twitter, pleasure can be had by sitting back and listening to the chattering masses. At other times, it may be productive to share what you know. In doing so, one of the twitterati may start a conversation with you.

Twitter's power resides in the content it generates, but also in the content that has been filtered through the sieve of your network. There are considerable benefits to finding out what others you respect and follow on Twitter think about world events, because social networks take you outside your regular milieu. For one thing, hearing what others have to say about specific issues opens up your worldview. It's no surprise that Twitter can be a way to bring new talent and ideas into an established circle of peers, almost like welcoming new employees.

\section{Where do you start on Twitter?}

First, set up a Twitter account and profile. Next, follow some friends and send some posts to them to try out the service. As you tweet, keep in mind the purpose of the service. Have you been reading something interesting somewhere? If it's on the Web, share the link with your followers. Have you got some great new ideas for research? Why not share a nugget of information and see what your social band of readers says about it?

To find and follow interesting and knowledgeable people, you can use the "Find people" tab or check to see who your friends are already following. Of course, it's always nice to be introduced to new people as a courtesy, and many social networks grow exponentially because of the tech-equivalent of six degrees of separation.

Although there are clearly no rules on Twitter, it is not an anarchic environment. Manners that pertain in other digital and face-to-face milieus also pertain to microblogging. However, it is fair to suggest that sharing is the whole reason that you are using Twitter. A good sense of humour is welcome, but misunderstandings can result if a joke doesn't translate in a new medium.

If the ideas that you share generate some excitement or debate, we suggest that you move the conversation to a better forum. In our experience, flaming is rare on Twitter, but there is still plenty of leeway for disagreement. Questions on Twitter are asked and answered, and useful resources are sought and recommended within your social 
network. Opinions are often presented and modified throughout the course of using Twitter [21]. If there is any cardinal rule, it might be to share openly and enjoy the open exchange of information with others.

Since Twitter users are able to post general and directed updates to their Twitter feed, a few options are available for customizing your posts. You can send out a general update that anyone can see. This is the most common tweet. However, you can also send out a direct (but still public) update when you decide to address or respond to a specific person or tweet. Directed posts and replies are indicated by the "@” symbol that is placed before a username at the start of your tweet. By using this format, others can see when you are responding to a specific person's tweet and can trace the thread back in time.

While directed updates are often used to communicate with specific people, they can be read by anyone, anywhere. Often two or more users will have conversations by posting updates directed to each other. Private posts to individuals can be sent using the "Direct Messages" feature on your profile. Private messages are also limited to a maximum of 140 characters [22].

\section{Social networking, educational, and collaboration tool}

Microblogging seems to have moved from its early perceived limitations. As an educational tool, Twitter communities are potentially powerful spaces for sharing useful information and knowledge. School teachers are beginning to experiment with microblogging as are academics. Microblogging is starting to gain some currency in all kinds of educational contexts. As a professional development tool, we believe that Twitter can play a role in informal "on-the-fly" learning in the workplace, particularly for health librarians who work in isolation [23].

Even though there are a number of informal communities that follow and interact with each other in Twitter, there are also a growing number of formal communities working together to share professional expertise, skills, and other workrelated information. Three groups of interest to health librarians include Librarians (http://twittgroups.com/group/librarians), the Library 2.0 Special Interest Group (IFLA) (http:// twittgroups.com/group/lib20sig), and the Medical Education group (http://twittgroups.com/group/meded). All of these groups maintain profiles or pages that contain links to all of the members within the group, useful resources, and even a customized stream of member tweets.

Browsing members of these groups helps identify other twitterers you might want to follow or add to your social network of contacts. To search for new groups, try the twittgroups site at http://twittgroups.com/. Since it is a fairly recent addition to the world of Twitter, we advise that you periodically check the Web site to browse or search for new groups.

In her Twittering Libraries wiki, Linda Brown, a Florida State University College of Information student, summarizes potential library uses of Twitter. Among her main topics of interest are tracking the pros and cons of Twitter. She has also put together an impressive list of American libraries using Twitter to communicate with their patrons [24].
All kinds of library-related information are shared on Twitter. New roles that health librarians play in distance education and online course development are frequent themes. With regard to information technologies, there is also considerable discussion about providing virtual reference in immersive worlds such as Second Life and the now defunct Google Lively.

Staying current with new social media can pose challenges to health librarians. Medical library twitterers can join the group tweet MedLib Geeks (http://twitter.com/medlibs) and keep up with changes to PubMed, upcoming health care events, and news about biomedical and health databases. Further, health libraries share information about new programs and alert each other about new Web resources.

Again, where do these health librarians find the time to read all of this information? Keep in mind that important developments are revealed on Twitter first and may show up later as pointers in blogs and RSS feeds. For those who want to stay connected and current, Twitter may fit the bill.

When Web 2.0 applications are discussed on Twitter, there often seems to be a flurry of chatter: how new tools are being used by various individuals and organizations, what their advantages and disadvantages are, and whether there are any problems to be aware of in their implementation. The fact is that many Twitter users are also big users of other social media, so this stands to reason.

Finally, you can follow other librarians by watching the tweets they send from conferences. We believe that when you follow group tweets from those attending library and information conferences anywhere in the world (e.g., SLA 2008 Conference; http://twitter.com/sla2008) you get a glimpse into the power of technology as well as the most recent opinions of thought leaders and innovators.

\section{RSS feed and bookmarking tool}

Although Twitter is specifically intended for microblogging, it also functions as an effective mechanism for getting updates from major news sites such as $\mathrm{CBC}, \mathrm{CNN}$, and the BBC. In that sense, Twitter's stream of constant news is its own kind of RSS feed. Being able to find the latest news from around the world is a particularly relevant application for health librarians. Breaking news is sent on Twitter, spreading virally. It acts as a kind of filtered RSS aggregating tool similar to Bloglines and iGoogle. Some health professionals enjoy the customized presentation of Twitter feeds more than the depersonalized formats seen on the Web. George Angus presents a compelling case for Twitter replacing RSS feeds for current news and efficient idea sharing [25].

Twitter makes it easy to check out what's happening among tech-savvy twitterers. If you don't follow Danny Sullivan, Tim O'Reilly, Clay Shirky, or other gurus, you can look up their tweets to see whether what they think is salient.

Given its potential as an index to current news, it will come as no surprise that Twitter can also be used as a bookmarking tool like Delicious or as a notepad on your desktop. One benefit is the ability to use Twitter quickly from your desktop or mobile device. It can be used to quickly jot down ideas to be remembered later. Twitter is a useful way to store ideas and keep track of resources and 
links found on the Web. You can use the Twitter "favorites" function to bookmark noteworthy tweets or tweets you want to examine more closely later.

\section{Search and "monitor" tool}

Being able to tap into the Twitter community is incredibly illuminating. In fact these days Twitter is starting to replace Google for me. If I want to know something I'll quite often ask my followers before I ask Google [26].

Some twitterers are using social networking tools (and their concomitant recommendations) in place of search engines. We find that Twitter users send out brief queries to their network and within short periods of time they are able to get satisfactory answers. This suggests that Twitter has some utility in terms of answering reference questions because you are drawing on a wide cross-section of knowledge in the twitosphere. Sometimes answers come in the form of recommended Web sites or referrals to other twitterers (often experts).

A number of search engine experts are using Twitter. Many are keen to have librarians within their social networks. By following your favourite bloggers and writers, you can monitor what projects they are working on and what they are saying to each other. In that sense, Twitter is a great way to get different perspectives on issues, whether it's about search tools such as Google and Yahoo or medical databases such as PubMed and MDConsult.

A word of caution about microblogging services-because they are public in nature, all posts (unless sent as private direct messages) are crawled by bots and searchable. Conversely, if you are interested in searching for what people within the Twitterverse are saying about specific topics, there is a dedicated search tool that you can use: http://search.twitter.com/.

A second way to "monitor" Twitter topics is to use a streaming search tool called Monitter (http://monitter.com/). By typing in words or phrases corresponding to your search request, you can monitor tweets in real time-tweets that are being created right now that contain the words you've typed in. We think of this as an (almost) live index to emerging threads of conversation and discourse on Twitter.

\section{Potential uses in medicine}

In the last year, Twitter began to reveal its potential in the fields of health and medicine. For example, a number of US hospitals are using Twitter to communicate with patrons, patients, and members in the community. The Hospital Social Network List currently lists more than 120 hospitals using Twitter [27].

Twitter is being used by medical students. Hungarian medical student Bertalan Mesko, author of the ScienceRoll blog, uses Twitter for a number of school-related purposes. He uses Twitter to follow other physicians, send out medical questions, and get feedback about his ideas. Mesko uses FriendFeed for something called the Medicine 2.0 microcarnival where information is aggregated (http:// friendfeed.com/rooms/medicine-2-0-microcarnival). $\overline{\text { Mesko }}$ says that Twitter supplements his RSS feeds, and it keeps him up-to-date on developments in Second Life and medicine-related events [28].

David Parry, a University of Texas professor, uses Twitter to communicate with his medical students. He writes about Twitter and microblogging on the Efficient MD blog [29]. Ves Dimov, a blogger at the Clinical Cases and Images blog, is a regular (prolific) twitterer and regularly blogs his "Selection of My Twitter Favorites" [30].

Another use for Twitter is to report on conferences in real time. One of the benefits of using Twitter at conferences is that the stream of tweets becomes an archive of opinions. Conference attendees can post to a collective Twitter feed by using what is known as the "hashtag convention" (http://hashtags.org). The collective feed from the 2008 Annual Meeting of the American College of Allergy, Asthma \& Immunology (ACAAI) is an example of how this convention is used. Because users at the meeting preface posts with "\#ACAAI", others can pull posts together by searching for the hashtag. For those not in attendance, sessions can be reviewed by looking at the Twitter feed. They can strike up "conversations" after the conference and share their thoughts with presenters, many of whom are on Twitter. Another example of using a hashtag for a conference is "\#NEJM", which identified tweets posted by attendees and followers during NEJM's Horizons Conference in 2008 [31].

We were impressed with the growing number of health organizations experimenting with Twitter. The American Red Cross uses Twitter (http://twitter.com/RedCross) to exchange minute-to-minute information about local disasters. The American Academy of Family Physicians (http://twitter.com/aafp) uses it to post medical news for both health practitioners and health consumers. The American Public Health Association (APHA) (http://twitter.com/PublicHealth) makes timely announcements about health campaigns (blood donation, flu shots, mental health), points to healthy living and safety resources (substance abuse, stress reduction, dietary advice, seat belts), and sends reminders to the public (reminders to check emergency supplies and smoke alarms when changing clocks from and to daylight savings time). The APHA also tweets as GetReady (https://twitter.com/GetReady), where it focuses specifically on their campaign to prepare Americans for health hazards, infectious diseases, and other health emergencies. The women's health feed (http://twitter.com/ womenshealth) is the Office of Women's Health of the US Department of Health and Human Services' official presence on Twitter.

The commercial world is using Twitter to disseminate health information and as a business strategy to draw visitors to their Web sites. MD Consult (http://twitter.com/mdconsult) is on Twitter and links to previews of health news and articles. Elsevier communicates with the library world through their library_connect user profile (http://twitter.com/library_connect).

\section{Use as a reference and library outreach tool}

A number of health librarians and bloggers are testing Twitter. At the University of Michigan Health Sciences Libraries, health librarians use it for a variety of purposes [32]. Using a "widget", you can feed Twitter into your library Web site or blog and conduct reference question-and-answer 
sessions. Do you want to make changes to your library Web site or policies? Why not get some suggestions and opinions from patrons using Twitter?

Twitter is a simple and concise way to push information out to people. Library patrons can get online help from librarians through a Twitter account. They can send messages asking about materials, and staff can return a tweet when information is found. Twitter can be used to announce library events, workshops, and reminders [33]. Further, Twitter can be used to update patrons on newly purchased materials. Got an emerging problem with your databases and electronic journal access? Let your social network or patrons know about it on Twitter. In doing so, you are strengthening your relationships as well as providing services in an innovative way.

Another way that some libraries are using Twitter is to send notices of overdue books rather than using e-mail. Some patrons may prefer this method. It's a simple way that Twitter can be used in place of existing technologies, although we have not tested this application of it. One of the obvious concerns is that it may be easy for patrons to miss messages.

\section{Political and social tool}

One of the more exciting aspects of Twitter is how it engages people in socially and politically significant issues. In fact, Twitter has been credited in building powerful political and social networks that mobilize globally at lightning speed. During the terrorist attacks in Mumbai, India, for example, Twitter was used as a mechanism to share information with the world about the unfolding drama [34].

Twitter has a number of potential applications for public announcements. Universities and governments are considering Twitter as a warning system in the event of terrorist attacks or natural disasters [35]. The US Federal Emergency Management Agency (FEMA) maintains a presence on Twitter (http://twitter.com/femainfocus) and provides updates on disaster and emergency preparedness, and specific events such as floods, earthquakes, landslides, and forest fires in the United States.

During the presidential primaries, millennials used Twitter to raise money for and track politicians. Using Twitter, Barack Obama's team mobilized itself for political rallies, giving them an organizational advantage over non-twittering opponents. In the last presidential campaign, the Political Voices of Women (PVW) blog provided examples of women blogging live events using Twitter (http://politicsanew.com/category/twitter/). The PVW site discusses the importance of Twitter in protecting American democracy [36].

Numerous politicians and government bodies are using Twitter. In the United Kingdom, DowningStreet (http:// twitter.com/DowningStreet) is the official Twitter feed of the British Prime Minister's Office. Justin Kerr-Stevens (@jkerrstevens), a communications strategist based in London, has his own Twitter feed (http://twitter.com/HMGOV), which he describes as an "unofficial service of official news feeds from UK Government." It collates news from various British government departments, agencies, and news services.
Closer to home, Canadian political figures are assuming a Twitter presence. The Prime Minister's Office (http:// twitter.com/PMWebUpdates), the national Liberal $\overline{\text { Party }}$ (http://twitter.com/LiberalHQ), Liberal Party leader Michael Ignatieff (http://twitter.com/M_Ignatieff), NDP leader Jack Layton (http://twitter.com/jacklayton), Green Party leader Elizabeth May (http://twitter.com/elizabethmay), and Bloc Québécois leader Gilles Duceppe (http://twitter.com/ gillesduceppe) all have Twitter accounts for their followers. Shortly before the 2008 federal election, bloggers noted that few Canadian politicians were on Twitter [37]. In 2009, this appears to be changing.

\section{Security and privacy concerns}

In health care, some serious potential troubles emerge with Twitter, particularly where patient information and confidentiality are concerned. What kinds of problems do health librarians have to be aware of on Twitter? Health librarians should be very careful about using Twitter to discuss reference questions. It may be possible to identify patients from the content of a tweet. Furthermore, be extremely wary of sharing any information from reference interviews or in meetings with physicians and other health professionals.

In the rush to adopt new information technologies in the digital age, many users do not stop to consider the potential difficulties resulting from the use of social media. Health librarians need to be mindful of what they are saying on social networking sites or they may create some conflicts for themselves at work. Some employees have actually been fired for saying certain things about their employers on Facebook and Twitter [38].

Access to social software tools is blocked by some public institutions, including government agencies, schools, and hospitals. The prevailing concern is that tools like Facebook and Twitter are connected to a drop in productivity in organizations. In the military, some of these sites have been banned owing to the enormous amounts of bandwidth they require for acceptable multimedia downloading times.

In 2008, Twitter suffered from a number of its own server problems, resulting in the dreaded "fail whale" being posted on its homepage [39]. As of early 2009, this problem, related to the sharp rise in the use of Twitter, seems to have been solved.

Twitter gathers information about its users. Twitter is a proprietary company with a profit motive. Facebook and other social networking sites consider the personal information provided on account profiles to be their property. Some users are surprised to learn that Twitter owns this information. Many social media sites reserve the right, in fact, to use your personal information and to sell it to third parties [40].

\section{Conclusion}

Social media present enormous challenges to health librarians and information professionals. In the case of microblogging, and Twitter specifically, the salient question is whether these tools have any proper application within the context of clinical care or evidence-based practice. We suspect that the increased use of mobile connectivity in research 
pods will at least increase the interest and experimentation with tools like Twitter.

Do we see Twitter as an important supplement to the e-tools we are using currently? Do the negatives and concerns around privacy and patient confidentiality outweigh the positives? The answer to these questions depends on the nature of the library services you offer and whether you believe they contribute to information overload. If a critical mass of our patrons begins to use these tools, we may be dragged into using them ourselves.

Some health librarians are justifiably concerned about the larger social and cultural issues related to social media. Where does all of this technology end? Will they ultimately be a drain on our psychic and intellectual energies? The need for some users of Web 2.0 technologies to be permanently "plugged in" does not mean that we have to be similarly connected. Does ambient access to information suggest an over-reliance on connective technologies? We argue they may build dependencies (addiction even) and inevitably lead to a further blurring of our public (professional) and private selves. As health librarians, is this something that we want to be promoting?

We acknowledge that many of these larger issues are having an impact in our field. However, Twitter, when used well, shows potential as a supplemental tool in our current information practices. Health librarians should be able to use it creatively for a range of activities, from doing outreach to getting updates from conferences. A number of physician bloggers and health 2.0 advocates are already using Twitter, although cautiously.

It would be unwise to ignore the most prominent information technologies in Web 2.0. Finally, our recommendation is to examine Twitter carefully and to try it out on a small scale within your organization. By taking the time to critique it carefully, health librarians will be able to assess its value to their workflow and information practice based on their professional and institutional goals.

\section{References}

1. Twitter Fan Wiki. Available from: http://twitter.pbwiki.com/.

2. Washburn S. Library Twitter. MaintainIT Project blog. 2007 Jun 24. Available from: http://www.maintainitproject.org/blog/ library-twitter.

3. Java A, Finin T. Why we Twitter: understanding microblogging usage and communities. In: Proceedings of the Joint 9th WEBKDD and 1st SNA-KDD Workshop 2007; 2007 Aug 12. Available from: http://ebiquity.umbc.edu/_file_directory_/papers/369.pdf.

4. Wikipedia. Twitter. 2009 Jan 6. Available from: http:// en.wikipedia.org/wiki/Twitter.

5. Ostrow A. Twitter's massive 2008: 752 percent growth. Mashable blog. 2009 Jan 9. Available from: http://mashable.com/2009/ 01/09/twitter-growth-2008/.

6. State of the Twittersphere. Q4 2008. Cambridge (Mass.): HubSpot. Available from: http://cdnqa.hubteam.com/State_of_the_ Twittersphere_by_HubSpot_Q4-2008.pdf.

7. Giustini D. 'Maple Leaf' Twitter: why aren't more Canadian librarians on Twitter? The Search Principle blog. 2008 Dec 31.
Available from: http://blogs.ubc.ca/dean/2008/12/maple-leaftwitter-why-arent-more-canadian-librarians-on-twitter/.

8. Wright MD. Of Canadian librarians and Twitter. meldinme blog. 1 Jan 2009. Available from: http://www.apexinformation.com/ meldinme/2009/01/of-canadian-librarians-and-twitter/.

9. Basu D. Top 20 Twitter posts of 2008. Search Engine Journal. 2008 Dec 30. Available from: http://www.searchenginejournal.com/ top-20-twitter-posts-of-2008/8221/.

10. Webb K. Webb's web: up for a little ambient intimacy? inCite. 2007 May;28(5):18-9.

11. Huberman BA, Romero DM, Wu F. Social networks that matter: Twitter under the microscope. First Monday. 2009 Jan;(14):1-5. Available from: http://firstmonday.org/htbin/ cgiwrap/bin/ojs/index.php/fm/article/view/2317/2063.

12. Skiba DJ. Nursing education 2.0: Twitter \& tweets. Can you post a nugget of knowledge in 140 characters or less? Nurs Educ Perspect. 2008 Mar-Apr;29(2):110-2.

13. Wikipedia. Yammer. 2009 Jan 8. Available from: http://en.wikipedia.org/wiki/Yammer.

14. UBC Health Library Wiki. Twitter. 2009 Jan 12. Available from: http://hlwiki.slais.ubc.ca/index.php/Twitter.

15. Twitter Fan Wiki. Twitter etiquette. 2009 Jan 9. Available from: http://twitter.pbwiki.com/Twitter+Etiquette.

16. Ingram M. Twitter: waste of time or social tool. Available from: http://www.mathewingram.com/work/2007/12/12/twitterwaste-of-time-or-social-tool/.

17. Problogger. Twitter is a waste of time. 2008 Jun 6. Available from: http://www.problogger.net/archives/2008/06/06/twitter-isa-waste-of-time/.

18. Green K. The rise of the miniblog: the founder of Twitter talks about upcoming features. Technology Review [blog]. 2008 Jul 9. Available from: http://www.technologyreview.com/Biztech/ 19022/page1/.

19. Teaching Librarian [blog]. Reference services and Twitter. 2007 Jun. Available from: http://www.teachinglibrarian.org/ weblog/2007/05/reference-services-and-twitter.html.

20. Miller CC. Will microblogging at work make you more productive? The New York Times - BITS [blog]. 2008 Oct 21. Available from: http://bits.blogs.nytimes.com/2008/10/21/willmicroblogging-at-work-make-you-more-productive/.

21. Young J. A professor's tips for using Twitter in the classroom. Chron High Educ. 2008 Jan. Available from: http:// chronicle.com/wiredcampus/article/2699/a-professors-tips-forusing-twitter-in-the-classroom.

22. UBC Health Library Wiki. Twitter. 2009 Jan 12. Available from: http://hlwiki.slais.ubc.ca/index.php/Twitter.

23. UBC Health Library Wiki. Twitter. 2009 Jan 12. Available from: http://hlwiki.slais.ubc.ca/index.php/Twitter.

24. Brown L. Twittering libraries. LIS5313 Course Wiki. 2009 Jan 9. Available from: http://lis5313.ci.fsu.edu/wiki/index.php/ Twittering_Libraries.

25. Angus G. Will Twitter replace RSS? TwiTip. 2008 Dec 11. Available from: http://www.twitip.com/will-twitter-replace-rss/. 
26. Rowse D. 5 ways I benefit from Twitter. TwiTip. 2008 Dec 4. Available from: http://www.twitip.com/benefits-twitter/.

27. Hospital Social Network List. 2009 Jan 7. Available from: http://ebennett.org/hsnl/.

28. Mesko B. 10 reasons why I use Twitter. ScienceRoll [blog]. Available from: http://scienceroll.com/2008/11/01/10-reasonswhy-i-use-twitter/.

29. Parry D. Twitter dispatches from New England. Efficient MD [blog]. Available from: http://efficientmd.blogspot.com/2008/ 10/twitter-dispatches-from-new-england.html.

30. Dimov V. Selection of my twitter favorites, edition 31. 2009 Jan 13. Clinical Cases and Images Blog. Available from: http://casesblog.blogspot.com/2009/01/selection-of-my-twitterfavorites_13.html.

31. Dimov V. NEJM Horizons Conference to Push Boundaries of Traditional Medical Publishing, Day 1. Clinical Cases and Images Blog. 2008 Dec 18. Available from: http://casesblog. blogspot.com/2008/12/nejm-horizons-conference-to-push.html.

32. Andersen P. Mobile healthcare education. Emerging Technologies Librarian [blog]. 2009 Jan 7. Available from: http://mblog.lib.umich.edu/etechlib/archives/twitter/index.html.

33. University of Minnesota Science and Engineering Library [blog]. Science and Engineering Library on Twitter - Library classes. 2008 Nov 20. Available from: http://blog.lib.umn.edu/ sciref/events/2008/11/science_and_engineering_librar.html.

34. Busari S. Tweeting the terror: how social media reacted to Mumbai. CNN. 2008 Nov 28. Available from: http://www.cnn. com/2008/WORLD/asiapcf/11/27/mumbai.twitter/index.html.

35. Williams M. Governments use Twitter for emergency alerts, traffic notices and more. Government Technology Magazine. 2009 Jan 7. Available from: http://www.govtech.com/gt/ 579338?topic $=117680$.

36. Viselli T. Protecting democracy with Twitter. The Political Voices of Women [blog]. 2008 Oct 18. Available from: http://politicsanew.com/2008/10/18/protecting-democracy-with-twitter/.

37. Male MD. Canadian politicians on Twitter. MasterMaq [blog]. 2008 Sept 8. Available from: http://blog.mastermaq.ca/2008/ 09/08/canadian-politicians-on-twitter/.

38. Terdiman D. Is there such as thing as being fired for Twittering? CNET News. 2008 Mar 26. Available from: http://news.cnet.com/8301-13772_3-9904138-52.html.

39. Scoble R. Twitter blames its users. Scobleizer [blog]. 2009 May 30. Available from: http://scobleizer.com/2008/05/30/ twitter-blames-its-users/.

40. Smale S, Greenberg S. Transient life: collecting and sharing personal information. In: ACM International Conference Proceeding Series, Vol. 206. Proceedings of the 18th Australia conference on Computer-Human Interaction: Design: Activities, Artefacts and Environments. New York: ACM; 2006. Available from: http://doi.acm.org/10.1145/1228175.1228184.

\section{Glossary}

bibliotwitosphere

fail whale when Twitter has down time or technical problems, the fail whale picture appears

microlearning learning that takes place in Web 2.0 microenvironments

microblogging a type of short blogging using a platform such as Twitter, Yammer, etc.

microposts a post of 140 characters or less

mistweet a post on Twitter that is a mistake

social media (or tools than enable being social online

social software)

tween a teen who uses Twitter

tweet a post on Twitter

tweeting to post a tweet

tweeple people on Twitter

tweeps the people in your social network

twirt to flirt on Twitter

twitterati high profile or famous people on Twitter

twitterer someone who uses Twitter

twitterverse the Twitter universe

twitosphere the Twitter community 